Jurnal Penelitian dan Pengabdian Kepada Masyarakat Bidang ilmu Pendidikan

\title{
Model Pembelajaran CIRC pada Mata Kuliah Apresiasi Sastra "Mantra Mbojo" untuk Meningkatkan Kreativitas Mahasiswa
}

\author{
Taufik1, Erwin $^{2}$, Husnul Khatimah ${ }^{3}$ \\ 1,Dosen Program Studi Pendidikan Bahasa Indonesia, STKIP Yapis Dompu \\ 2,Dosen Program Studi Pendidikan Jasmani Kesehatan dan Rekreasi, STKIP Yapis Dompu \\ ${ }^{3}$ Dosen Program Studi Pendidikan Sejarah, STKIP Yapis Dompu \\ E-mail: taufikbima25@g,mail.com
}

Article History: Received: 2020-10-09 || Revised: 2020-11-03 || Published: 2020-11-19

Sejarah Artikel : Diterima: 2020-10-09 || Direvisi: 2020-11-03 || Dipublikasi: 2020-11-19

\begin{abstract}
This research is a research using the Cooperative Integrated Reading and Composition (CIRC) learning model in the Literary Appreciation Course "Mantra Mbojo" to Increase Student Creativity. This research aims to give students freedom to take creative, scientific thinking steps by collecting data from learning outcomes, then students can interpret, analyze, and finally arrive at a conclusion, so it is expected that student learning achievement will increase. The type of research used in this research is Classroom Action Research (CAR). The results obtained in this study are student creativity after the implementation of the CIRC learning model in the old literature course Mantra Mbojo, fifth semester students of the Indonesian Language and Literature Education (P-BSI) study program. STKIP Yapis Dompu has increased. In the first cycle, it has not yet reached classical completeness, because the completeness is $54.1 \%, 11$ of the 24 students who did not complete it. In cycle II, it has achieved classical completeness, with completeness of $87.5 \%$, namely from 24 students who did not complete 3 students. So from cycle I to cycle II an increase of $33.4 \%$.
\end{abstract}

Keywords: CIRC Learning Model, Mbojo Mantra Creativity

\begin{abstract}
Abstrak
Penelitian ini adalah penelitian dengan pemanfaatan model pembelajaran Cooperative Integrated Reading and Composition (CIRC) pada Mata Kuliah Apresiasi Sastra "Mantra Mbojo" untuk Meningkatkan Kreativitas Mahasiswa ini bertujuan untuk memberikan kebebasan pada mahasiswa untuk melakukan langkah-langkah berpikir kreatif, ilmiah dengan cara mengumpulkan data dari hasil pembelajaran, kemudian mahasiswa dapat menafsirkan, menganalisis, dan akhirnya sampai pada suatu kesimpulan, sehingga diharapkan prestasi belajar mahasiswa menjadi meningkat. Jenis penelitian yang digunakan pada penelitian ini adalah jenis Penelitian Tindakan Kelas (PTK) hasil yang didapatkan dalam penelitian ini adalah kreativitas mahasiswa setelah diterapkannya model pembelajaran CIRC pada matakuliah sastra lama Mantra Mbojo mahasiswa semester V program studi Pendidikan Bahasa dan Sastra Indonesia (P-BSI) STKIP Yapis Dompu mengalami peningkatan. Pada siklus I belum mencapai ketuntasan klasikal, karena ketuntasannya sebesar 54,1\%, yaitu dari 24 mahasiswa yang tidak tuntas 11 mahasiswa. Pada siklus II telah mencapai ketuntasan klasikal, dengan ketuntasannya sebesar $87,5 \%$ yaitu dari 24 mahasiswa yang tidak tuntas 3 mahasiswa. Jadi dari siklus I ke siklus II mengalami peningkatan sebesar 33,4\%.
\end{abstract}

Kata kunci: Model Pembelajaran CIRC, Mantra Mbojo, Kreativitas

\section{PENDAHULUAN}

Predikat yang melekat pada seorang dosen profesional tentu saja harus diimbangi dengan kinerja, prestasi serta kompetensi yang mumpuni. Dalam pendidikan formal, dosen merupakan sala satu komponen pendidikan yang memiliki peranan penting dalam aktifitas pembelajaran di perguan tinggi.Seiring dengan tuntutan profesionalisme, tentunya semangat membelajarkan mahasiswa sesuai dengan kaidah-kaidah dalam kurikulum yang dijalankan. Oleh karena itu, aplikasi pembelajaran harus diwujudkan dalam persiapan, pelaksanaan, dan evaluasi pembelajaran. Dalam UU No. 14 tahun 2005 Tentang Guru dan Dosen menegaskan bahwa "Dalam 
melaksanakan tugas keprofesionalan, guru berkewajiban merencanakan pembelajaran, melaksanakan proses pembelajaran yang bermutu, serta menilai dan mengevalusai hasil pembelajaran serta meningkatkan dan mengembangkan kualifikasi akademik dan kompetensi secara berkelanjutan sejalan dengan perkembangan ilmu pengetahuan, teknologi, dan seni". Maka jelaslah proses pendidikan tidak akan terlaksana dengan baik jika kewajiban guru diabaikan. Guru harus tulus mengabdikan dirinya, memusatkan perhatian terhadap sepenuhnya terhadap proses pendidikan.

Peningkatan mutu pendidikan haruslah dilakukan dengan menggerakkan seluruh komponen yang menjadi subsistem dalam suatu sistem mutu pendidikan. Fasilitator yang pertama dan utama dalam peningkatan mutu pendidikan adalah dosen. Dosen adalah ujung tombak pendidikan, sebab dosen secara langsung mempengaruhi, membina, dan mengembangkan kemampuan siswa agar menjadi manusia yang cerdas, terampil dan bermoral. dosen harus mempunyai kemampuan dasar yang diperlukan sebagai pendidik dan pengajar. Sebagai pengajar, paling tidak dosen harus menguasai bahan yang diajarkannya dan terampil dalam hal mengajarkannya. Dosen juga harus memuwujdkan proses belajar mengajar yang efektif dan efisien, agar pengajaran berjalan dengan baik. Pengajaran berjalan baik meliputi pengajaran mahasiswa, bagaimana belajar, bagaimana mengingat, bagaimana berfikir dan bagaimana memotivasi diri mereka sendiri (Yamin dan Anshari, 2009). Oleh karena itu, dalam proses belajar mengajar penentuan model pembelajaran harus disesuaikan dengan materi yang diajarkan.

Model Pembelajaran Cooperative Integrated Reading and Composition (CIRC) adalah salah satu model pembelajaran kooperatif terpadu membaca dan menulis, dimana mahasiswa di bagi menjadi beberapa kelompok untuk meningkatkan kemampuan pemahaman dalam membaca, menulis, memahami kosa kata, dan seni berbahasa. Menurut Uno dan Muhamad (2011), Model Cooperative Integrated Reading and Composition (CIRC) merupakan salah satu tipe model pembelajaran kooperatif yang merupakan komposisi terpadu membaca dan menulis secara kooperatif (kelompok), yaitu membaca materi yang diajarkan dari berbagai sumber dan selanjutnya menuliskannya ke dalam bentuk tulisan yang dilakukan secara kooperatif. Model ini dikembangkan untuk meningkatkan kemampuan berpikir kreatif mahasiswa. model pembelajran CIRC merupakan model pembelajaran yang lebih cocok dan tepat diaplikasikan pada mata pelajaran Bahasa Indonesia khusus pada materi membaca, menemukan ide pokok, pokok pikiran, atau tema sebuah wacana, Kurniasih \& Sani (dalam I Gede Agus Raka Putrawan. 2017) Pembelajaran dengan memanfaatkan model pembelajaran Cooperative Integrated Reading and Composition (CIRC) pada Mata Kuliah Apresiasi Sastra "Mantra Mbojo" untuk Meningkatkan Kreativitas Mahasiswa ini bertujuan untuk memberikan kebebasan pada mahasiswa untuk melakukan langkah-langkah berpikir kreatif, ilmiah dengan cara mengumpulkan data dari hasil pembelajaran, kemudian mahasiswa dapat menafsirkan, menganalisis, dan akhirnya sampai pada suatu kesimpulan, sehingga diharapkan prestasi belajar mahasiswa menjadi meningkat.

Berdasarkan latar belakang di atas, adapun tujuan penelitian ini yaitu untuk menerapkan model pembelajaran Cooperative Integrated Reading and Composition (CIRC) pada Mata Kuliah Apresiasi Sastra "Mantra Mbojo" untuk Meningkatkan Kreativitas Mahasiswa Semester V Program Studi Pendidikan Bahasa dan Sastra Indonesia STKIP Yapis Dompu Tahun Ajaran 2019-2020.

\section{METODE PENELITIAN}

\section{A. Jenis Penelitian}

Jenis penelitian ini adalah jenis Penelitian Tindakan Kelas (PTK). Menurut Arikunto (2010) ada tiga pengertian yang bisa dipakai menjelaskan PTK sesuai dengan ketiga kata yang terdapat didalamnya, yaitu: 
a. Penelitian, menunjuk pada suatu kegiatan mencermati suatu objek dengan menggunakan cara dan aturan metodologi tertentu untuk memperoleh data atau informasi yang bermanfaat untuk meningkatkan mutu suatu hal.

b. Tindakan, menunjuk pada sesuatu gerak kegiatan (dalam hal ini berbentuk rangkaian siklus kegiatan untuk mahasiswa) yang sengaja dilakukan dengan tujuan tertentu.

c. Kelas, menunjuk suatu tempat (tidak selalu kelas atau ruangan) tetapi, seperti yang sudah dikenal dalam dunia pendidikan, kelas merujuk pada sekumpulan mahasiswa yang dalam waktu yang sama, menerima pelajaran yang sama dari dosen yang sama pula.

Dari tiga pengertian di atas, dapat disimpulkan bahwa PTK merupakan suatu pencermatan terhadap kegiatan belajar berupa sebuah tindakan, yang sengaja dimunculkan dan terjadi dalam sebuah kelas secara bersama. Sedangkan, menurut Suhardjono (2010) penelitian tindakan kelas (PTK) adalah penelitian tindakan (action research) yang dilakukan dengan tujuan memperbaiki mutu praktik pembelajaran di kelasnya. Mulyatiningsih (2011) menyatakan karakteristik penelitian tindakan kelas sebagai berikut:

a. Problema yang diangkat adalah problema yang dihadapi oleh dosen dan mahasiswa di kelas dalam kegiatan belajar mengajar sehari-hari.

b. Penelitian tindakan diambil berdasarkan pada hasil evaluasi dan refleksi diri.

c. Penelitian dilakukan dalam beberapa putaran waktu (siklus) sampai permasalahan dapat diatasi.

d. Penelitian bertujuan untuk pemberdayaan, perbaikan, peningkatan mutu, dan peningkatan kemampuan/kompetensi.

e. Penelitian tindakan kelas bersifat kolaboratif yaitu melibatkan dosen, peneliti dan mahasiswa yang mempunyai tugas, tanggungjawab, dan kepentingan yang berbeda tetapi tujuannya sama yaitu memecahkan masalah untuk peningkatan kualitas pembelajaran dikampus.

Dari beberapa pendapat yang telah dijelaskan, maka dapatdisimpulkan bahwa penelitian tindakan kelas adalah penelitian yang dilaksanakan dalam beberapa putaran waktu (siklus) di suatu tempat dimana terdapat sekumpulan mahasiswa menerima pelajaran dari dosen dengan tujuan untuk perbaikan atau meningkatkan mutu di kelas tersebut.

\section{B. Desain Penelitian}

Keempat tahap tersebut dipandang sebagai suatu siklus. Pada penelitian ini direncanakan menggunakan dua siklus. Apabila dalam dua siklus ketuntasan hasil belajar dan aktivitas belajar mahasiswa belum tercapai, maka dilanjutkan siklus ketiga dan seterusnya.

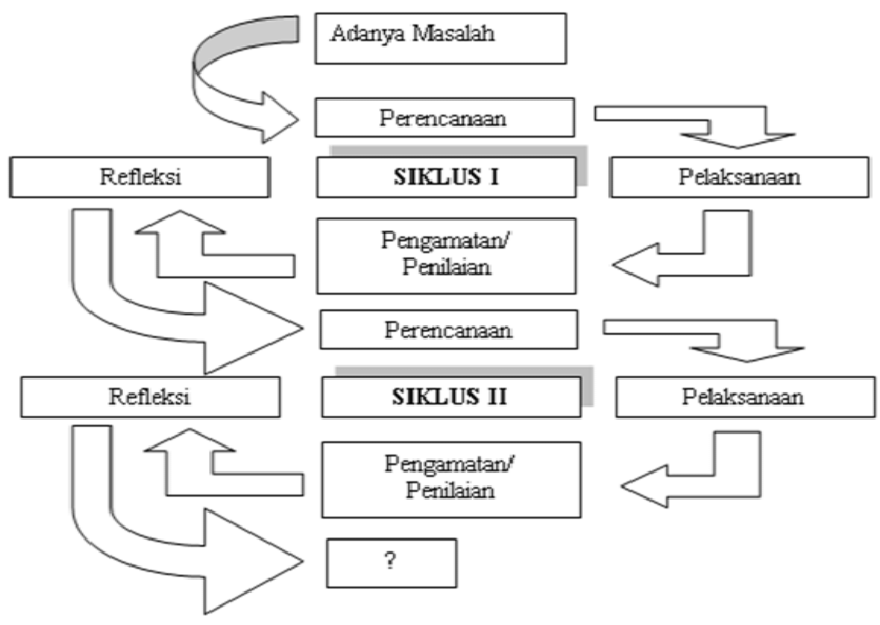

Gambar 1. Prosedur Penelitian (Arikunto, 2010) 


\section{Subjek dan Lokasi Penelitian}

Subyek penelitian adalah orang yang merespon atau menjawab pertanyaan tertulis maupun lisan (Arikunto, 1998). Jadi subyek penelitian adalah orang yang dapat memberikan keterangan, penjelasan atau tanggung jawab terhadap suatu permasalahan yang diselidiki. Adapun subyek penelitian adalah seluruh mahasiswa semester V program studi PENDIDIKAN BAHASA DAN SASTRA INDONESIA STKIP Yapis Dompu Tahun ajaran 2019-2020.

\section{Prosedur Penelitian}

1. Studi Pendahuluan

Dalam kegiatan ini, beberapa hal yang dilakukan adalah melakukan analisis awal akhir guna mempersiapkan solusi untuk menyelesaikan masalah yang di hadapi oleh peneliti, solusi yang akan ditawarkan berupa perangkat pembelajaran model Cooperative Integrated Reading and Composition (CIRC) pada Materi Puisi Lama "Mantra Mbojo" untuk Meningkatkan Kreativitas Mahasiswa.

2. Pelaksanaan Siklus I

a. Perencanaan

Agar pelaksanaan tindakan dalam PTK dapat berjalan dengan baik, maka perlu adanya perencanaan dan persiapan tindakan dengan baik. Langkah-langkah persiapan yang perlu ditempuh adalah sebagai berikut:

1) Menyiapkan silabus kelas VIII semester genap.

2) Menyusun perangkat pembelajaran dengan menggunakan pendekatan open-ended (RPP, LKS, soal tes individu (try out)

3) Melaksanakan try out di kelas yang berbeda dan telah menempuh pokok bahasan kubus dan balok.

4) Menyusun daftar kelompok belajar.

5) Membuat pedoman observasi dan pedoman wawancara.

Di sini peneliti melakukan pembentukan kelompok sebelum proses pembelajaran berlangsung. Hal ini dilakukan peneliti agar pada saat kegiatan inti waktu tidak terbuang untuk pembentukan kelompok, sehingga pembelajaran dapat berlangsung secara optimal.

b. Pelaksanaan Tindakan

Tindakan dilakukan pada tahap ini adalah melaksanakan rencana penelitian yang telah disusun yaitu melaksanakan proses belajar mengajar menggunakan model cooperative integrated reading and composition CIRC pada materi puisi lama "mantra Mbojo" dalam meningkatkan kreativitas mahasiswa.

c. Pengamatan

Kegiatan pengamatan dilakukan bersamaan dengan pelaksanaan tindakan. Dalam penelitian ini peneliti dibantu oleh observer yang sebelumnya telah diberi pengarahan mengenai model cooperative integrated reading and composition (CIRC) pada materi puisi lama "mantra Mbojo" yang akan dilakukan. Dalam pelaksanaannya menggunakan lembar observasi yang telah disediakan. Kegiatan yang dilakukan oleh observer adalah mengamati aktivitas belajar dan hasil belajar mahasiswa dalam mengikuti proses pembelajaran dengan kriteria yang sudah ditentukan.

d. Refleksi

Tahapan ini dimaksudkan untuk mengkaji secara menyeluruh tindakan yang telah dilakukan, berdasarkan data yang telah terkumpul, kemudian dilakukan evaluasi guna menyempurnakan tindakan berikutnya. Hasil dari kegiatan refleksi ini, akan dijadikan dasar 
untuk merencanakan tindakan selanjutnya, yaitu pelaksanaan tindakan pada siklus berikutnya.

3. Pelaksanaan Siklus II

Pelaksanaan siklus II dilaksanakan apabila pada siklus pertama aktivitas dan hasil belajar mahasiswa tidak mencapai ketuntasan klasikal. Proses pelaksanaan siklus kedua dilaksanakan sama dengan proses pelaksanaan siklus pertama. Pelaksaanaan siklus akan tetap berlangsung sampai aktivitas dan hasil belajar mahasiswa bisa mencapai ketuntasan belajarnya.

4. Kriteria Ketuntasan

Kriteria ketuntasan dalam penelitian ini sebagai berikut:

a. Daya serap perorangan yaitu seorang siswa dikatakan tuntas belajar apabila telah mencapai skor $\geq 65$ dari skor maksimal 100 .

b. Daya serap klasikal yaitu kelas dikatakan tuntas belajar apabila terdapat minimal $80 \%$ mahasiswa yang telah mencapai $\geq 65$ dari skor maksimal 100 .

\section{E. Instrumen Penelitian}

Untuk pengumpulan data dalam rangka mendaptkan informasi, digunakanlah instrumen. Instrumen yang diperlukan antara lain:

a. Lembar Observasi

Lembar observasi digunakan untuk memperoleh informasi berkaitan dengan kegiatan mengajar belajar selama uji coba terdiri dari:

a. Lembar observasi aktivitas mahasiswa

b. Lembar observasi kemampuan dosen mengelola pembelajaran

b. Soal Tes Kreativitas Mahasiswa (TKM)

Tes Kreativitas Mahasiswa adalah serangkaian pertanyaan atau latihan yang digunakan untuk mengukur keterampilan pengetahuan, intelegensi, kemampuan atau bakat pada materi puisi lama "mantra Mbojo" yang dimliki oleh individu maupun kelompok yang didalamnya mengandung unsur kreativitas.

c. Worksheet

Lembar kerja mahasiswa adalah serangkaian soal-soal yang bertujuan untuk melatih kemampuan berpikir kreatif mahasiswa dalam memahami materi puisi lama "mantra Mbojo" yang disampaikan oleh dosen.

\section{F. Metode Pengumpulan Data}

Menurut (Arikunto, 2006) metode pengumpulan data adalah bagaimana cara peneliti menentukan metode setepat-tepatnya untuk memperoleh data. Adapun metode yang digunakan dalam penelitian ini adalah observasi, wawancara dan tes. Tes kreativitas dalam penelitian ini digunakan untuk mengetahui hasil belajar mahasiswa setelah mengikuti pembelajaran dengan model Cooperative Integrated Reading and Composition (CIRC) untuk meningkatkan kreativitas mahasiswa. Tes yang baik harus memenuhi kriteria sebagai berikut:

a. Validitas Butir Tes

Sebuah tes dikatakan memiliki validitas yang baik jika hasilnya sesuai dengan kriteria yang diukur (Arikunto, 2005). Oleh karena itu, suatu butir tes memiliki validitas yang baik jika sesuai dengan pengukuran tes secara keseluruhan. Salah satu teknik yang digunakan untuk menentukan validitas butir suatu tes adalah dengan mengkorelasikan skor yang diperoleh pada setiap butir dengan skor total. Rumus yang digunakan adalah rumus korelasi Product moment, yaitu: 


$$
r_{x y}=\quad \frac{\cdots-\cdots-\left(\sum X\right)\left(\sum^{Y}\right.}{N_{\Sigma} X^{-}-\left(\sum X\right)^{2} N_{\sum} Y^{2}-\left(\sum Y\right)^{2}}
$$

Keterangan:

$$
\begin{aligned}
& X=\text { skor butir } \\
& Y=\text { skor total } \\
& N=\text { banyak mahasiswa yang mengikuti tes } \\
& r_{X y}=\text { koefisien korelasi skor butir dan skor total. }
\end{aligned}
$$

Nilai rxy diinterpretasikan sebagai berikut. (Ratumanan dan Laurens, 2006)

$0,80 \leq r_{x y} \leq 1,00$ : validitas butir tes sangat tinggi

$0,60 \leq r_{x y}<0,80$ : validitas butir tes tinggi

$0,40 \leq r_{x y}<0,60$ : validitas butir tes cukup

$0,20 \leq r_{x y}<0,40$ : validitas butir tes rendah

$0,00 \leq r_{x y}<0,20$ : validitas butir tes sangat rendah

b. Reliabilitas Tes

Koefisien reliabilitas suatu tesbentuk uraian dapat ditaksir dengan menggunakan rumus Alpha yaitu sebagai berikut:

$\operatorname{RII}(\mathrm{a})=\left(\frac{n}{(n-1)}\right)\left(1-\frac{\Sigma \sigma_{1}^{2}}{\sigma_{1}^{2}}\right)$ (Arikunto, 2005)

Keterangan:

$$
\begin{array}{ll}
\operatorname{RII}(\mathrm{a}) & =\text { reliabilitas tes yang dicari } \\
\mathrm{N} & =\text { banyak butir tes } \\
\sum_{\sigma_{1}^{2}} \sigma_{1}^{z} & =\text { jumlah varians tiap-tiap item } \\
& =\text { varians total }
\end{array}
$$

Interpretasi koefisien reliabilitas tes menggunakan kategori berikut (Ratumanan dan Laurens, 2006: 39)

$$
\begin{aligned}
& 0,80<\text { RII ( ) } \leq 1.00 \text { : reliabilitas tes tinggi } \\
& 0,40<\text { RII ( ) } \leq 8,00 \text { : reliabilitas tes cukup } \\
& 0,00<\text { RII ( ) } \leq 0,40 \text { : reliabilitas tes rendah }
\end{aligned}
$$

c. Sensitivitas Butir Tes

Sensitivitas butir adalah ukuran seberapa baik butir soal dapat membedakan tingkat kemampuan mahasiswa sebelum menerima pembelajaran. Untuk menentukan sensitivitas butir tes digunakan rumus:

$$
\mathrm{S} \quad=\frac{\sum S_{e s}-S_{e b}}{N\left(S k o r_{\max }-S k o r_{\min }\right)}
$$


Keterangan:

$S \quad=$ indeks sensitivitas butir

$\mathrm{N} \quad=$ banyaknya mahasiswa

$\sum S_{E S}=$ jumlah skor subjek sesudah proses pembelajaran

$\sum S_{e b}=$ jumlah skor subjek sebelum proses pembelajaran

Skor $_{\max }=$ skor maksimal yang dicapai mahasiswa

Skor $_{\min }=$ skor minimum yang dicapai mahasiswa

\section{G. Teknik Analisis Data}

Untuk menghitung persentase ketuntasan hasil belajar siswa secara klasikal menggunakan rumus:

$$
P=\frac{n}{N} \times 100 \%
$$

(Hobri, 2007)

Keterangan:

$\mathrm{P}=$ Presentase Ketuntasan Belajar Secara Klasikal

$\mathrm{n}$ = Jumlah Mahasiswa yang Tuntas Belajar

$\mathrm{N}=$ Jumlah Seluruh Mahasiswa

\section{HASIL DAN PEMBAHASAN}

\section{A. Hasil Uji Coba Tes Kreativitas Mahasiswa (TKM)}

Tujuan dari uji coba TKM adalah untuk memperoleh data tentang validitas butir tes, reliabilitas tes, dan sensitivitas butir tes, ketiga indikator ini merupakan penentu keputusan apakah tes yang dikembangkan perlu direvisi atau tidak. Hasil analisis validitas butir tes, reliabilitas tes, dan sensitifitas butir tes sebagai berikut:

1. Validitas

Berdasarkan rumus korelasi product moment diperoleh validitas setiap butir tes sebagai berikut:

Tabel 1. Hasil Analisis Butir Tes

\begin{tabular}{lccccc} 
No Soal & $\mathbf{1}$ & $\mathbf{2}$ & $\mathbf{3}$ & $\mathbf{4}$ & $\mathbf{5}$ \\
\hline $\mathrm{r}_{\mathrm{xy}}$ & 0,61 & 0,67 & 0,63 & 0,58 & 0,47 \\
\hline Interpretasi & Tinggi & Tinggi & Tinggi & Cukup & Cukup \\
\hline
\end{tabular}

Berdasarkan Tabel.1 di atas, validitas dari masing-masing butir soal TKM berada pada kategori cukup dan tinggi. Dengan demikian semua butir soal TKM valid.

2. Reliabilitas

Perhitungan reliabilitas tes menunjukkan koefisien reliabilitas sebesar 0,87. Angka ini menunjukkan bahwa reliabilitas instrumen TKM termasuk dalam kategori "tinggi". Dengan demikian, instrumen TKM dapat dikatakan reliabel.

3. Sensitivitas

Sensitivitas setiap butir tes dapat dilihat pada Tabel berikut ini: 
Tabel 2. Sensitivitas Butir Tes

\begin{tabular}{cccccc}
\hline No. Soal & $\mathbf{1}$ & $\mathbf{2}$ & $\mathbf{3}$ & $\mathbf{4}$ & $\mathbf{5}$ \\
\hline Sensitivitas & 0,67 & 0,68 & 0,59 & 0,47 & 0,43 \\
\hline \multirow{2}{*}{ Interpretasi } & Sensitif & Sensitif & Sensitif & Sensitif & \multirow{2}{*}{ Sensitif } \\
\hline
\end{tabular}

Pada Tabel 2. menunjukkan bahwa setiap butir tes sensitif terhadap pembelajaran. Berdasarkan hasil analisis validitas butir tes, reliabilitas tes, dan sensitivitas butir tes. Maka, TKM dapat dikategorikan baik.

\section{B. Hasil Belajar (Kreativitas Mahasiswa)}

Hasil belajar yang ditunjukkan oleh nilai postes pada tes akhir siklus adalah sebagai berikut:

Tebel 3. Nilai Tes Kreativitas Mahasiswa (TKM)

\begin{tabular}{cc}
\hline Nilai & Pos-tes \\
\hline Tertinggi & 100 \\
\hline Terendah & 65 \\
\hline Rata-rata & $\mathbf{8 2 , 5}$ \\
\hline
\end{tabular}

Seperti yang telah diuraikan di atas, bahwa belajar mahasiswa dikatakan tuntas secara individual, jika skor postes yang diperoleh paling sedikit 70 dari skor tertinggi, yaitu 100 . Sedangkan suatu kelompok (kelas) dikatakan tuntas belajarnya secara klasikal jika 85\% mahasiswa tuntas secara individual. Ketuntasan belajar mahasiswa baik secara individual maupun secara klasikal ditunjukkan dalam Tabel 4

Tabel 4. Ketuntasan Hasil Belajar

\begin{tabular}{lll}
\hline Indikator & Siklus I & Siklus II \\
\hline Banyaknya mahasiswa yang tuntas secara individu & $\begin{array}{l}24 \text { mahasiswa } \\
\text { atau 54,1\% }\end{array}$ & $\begin{array}{l}\text { 24 mahasiswa } \\
\text { atau 87,5\% }\end{array}$ \\
\hline $\begin{array}{l}\text { Banyaknya mahasiswa yang tidak tuntas secara } \\
\text { individu }\end{array}$ & $\begin{array}{l}11 \text { mahasiswa } \\
\text { atau 45,9\% }\end{array}$ & $\begin{array}{l}\text { 3 mahasiswa } \\
\text { atau } 12,5 \%\end{array}$ \\
\hline Ketuntasan belajar secara klasikal & Tidak tuntas & Tuntas \\
\hline
\end{tabular}

\section{SIMPULAN DAN SARAN}

\section{A. Simpulan}

Berdasarkan hasil penelitian dan pembahasan, dapat diambil kesimpulan sebagai berikut: Kreativitas mahasiswa setelah diterapkannya model pembelajaran CIRC pada matakuliah sastra lama Mantra Mbojo mahasiswa semester V program studi Pendidikan Bahasa dan Sastra Indoneisa (P-BSI) STKIP Yapis Dompu mengalami peningkatan. Pada siklus I belum mencapai ketuntasan klasikal, karena ketuntasannya sebesar $54,1 \%$ yaitu dari 24 mahasiswa yang tidak tuntas 11 mahasiswa. Pada siklus II telah mencapai ketuntasan klasikal, dengan ketuntasannya sebesar 87,5\% yaitu dari 24 mahasiswa yang tidak tuntas 3 mahasiswa. Jadi dari siklus I ke siklus II mengalami peningkatan sebesar $33,4 \%$. 
B. Saran

Penelitian ini dapat dimanfaatkan sebagai tambahan pengetahuan dalam menambah wawasan tentang model pembelajaran Cooperative Integrated Reading and Composition (CIRC) pada Mata Kuliah Apresiasi Sastra "Mantra Mbojo".

\section{DAFTAR RUJUKAN}

Arikunto, S. 2005. Dasar-dasar Evaluasi Pendidikan Matematika. Edisi Revisi. Jakarta: Bumi Aksara.

Arikunto, dkk. 2010. Penelitian Tindakan Kelas. Jakarta: Bumi Aksara.

Arikunto. 2006. Prosedur Penelitian Suatu Pendekatan Praktek. Jakarta: PT. Rineka Cipta.

Hobri. 2007. Penelitian Tindakan Kelas (PTK). Jember: Pena Salsabila

Mulyatiningsih, E. 2011. Metode Penelitian Terapan Bidang Pendidikan. Yogyakarta: Alfabeta.

Puspitasari, Laksmi. 2012. "Pengaruh Model Problem Based Learning Terhadap Kemampuan Berpikir Kreatif Siswa Mata Pelajaran Biologi Kelas X SMA Negeri 2 Surakarta". [Skripsi dipublikasikan]. Universitas Sebelas Maret. Surakarta.

Putrawan, Raka A. Gede I, dkk. 2017. Pengaruh Model Pembelajaran CIRC (Cooperative Integrated Reading and Composition) terhadap Literasi Siswa Kelas III SD. e-Journal PGSD Universitas Pendidikan Ganesha. Vol. 5 No. 2 Tahun: 2017

Ratumanan, dkk. 2003. Evaluasi Hasil Belajar yang Relevan dengan Kurikulum Berbasis Kompetensi. Surabaya: YP3IT dan Unesa University Press.

Ratumanan, dkk. 2006. Evaluasi Hasil Belajar yang Relevan dengan Kurikulum Berbasis Kompetensi. Surabaya: YP3IT dan Unesa University Press.

Uno, H, Nurdin, M. 2011. "Belajar dengan Pendekatan PAILKEM". Jakarta: Bumi Aksara.

Yamin, dan Ansari, B. 2009. Teknik Mengembangkan Kemampuan Individual Siswa. Jakarta: Gaung Persada Press. 